\title{
Unhealthy Lifestyle Associated with Higher Intake of Sugar-Sweetened Beverages among Malaysian School-Aged Adolescents
}

\author{
Wan Ying Gan * (1), Siti Fathiah Mohamed and Leh Shii Law \\ Department of Nutrition and Dietetics, Faculty of Medicine and Health Sciences, Universiti Putra Malaysia, \\ Serdang 43400, Malaysia \\ * Correspondence: wanying@upm.edu.my; Tel.: +603-8947-2469
}

Received: 25 June 2019; Accepted: 2 August 2019; Published: 4 August 2019

\begin{abstract}
High consumption of sugar-sweetened beverages (SSBs) among adolescents has turned into a global concern due to its negative impact on health. This cross-sectional study determined the amount of SSB consumption among adolescents and its associated factors. A total of 421 adolescents aged $13.3 \pm 1.3$ years $(41.8 \%$ males, $58.2 \%$ females) completed a self-administered questionnaire on sociodemographic characteristics, physical activity, screen-viewing behavior, sleep quality, frequency of eating at fast food restaurants, home food availability, peer social pressure, parenting practice, and SSB consumption. Weight and height were measured. Results showed that the mean daily consumption of SSBs among adolescents was $1038.15 \pm 725.55 \mathrm{~mL}$. The most commonly consumed SSB was malted drink, while the least commonly consumed SSB was instant coffee. The multiple linear regression results revealed that younger age $(\beta=-0.204, p<0.001)$, higher physical activity $(\beta=0.125, p=0.022)$, higher screen time $(\beta=0.147, p=0.007)$, poorer sleep quality $(\beta=0.228$, $p<0.001)$, and unhealthy home food availability $(\beta=0.118, p=0.032)$ were associated with a higher SSB intake. Therefore, promoting a healthy lifestyle may help to reduce the excessive consumption of SSBs among adolescents.
\end{abstract}

Keywords: Sugar-sweetened beverages (SSBs); obesity; physical activity; screen time; sleep quality; fast food; Malaysian adolescents

\section{Introduction}

Sugar-sweetened beverages (SSBs) are defined as any beverage that has added sugar or caloric sweetener such as "sucrose ( $50 \%$ glucose, $50 \%$ fructose), high-fructose corn syrup (HFCS; most often $45 \%$ glucose and $55 \%$ fructose), or fruit juice concentrates by manufacturers, establishments, or individuals and usually contain $>25 \mathrm{kcal}$ per 8 fluid ounces" [1]. Some instances of SSBs are calorie-containing carbonated drinks, sweetened milk, sweetened teas and coffees, sport drinks, energy drinks (energy juices and energy sodas), fruit-flavored drinks (fruit-flavored, non-carbonated, and non-alcoholic fruit drinks), sweetened fruit juices (nectars and mixed juices, juices with added caloric sweeteners, and non-dairy-based fruit smoothies), vitamin water drinks, sodas, and beverages with added sugar [1-4].

Sugar-sweetened beverages contribute to calories in diet, wherein consumption in large amounts leads to poor diet quality and obesity due to the added sugar content with little or nil nutritional value while being high in calories [1,2]. Apart from obesity, a high consumption of SSBs has adverse effects on children's health, such as increased likelihood of dental caries, insulin resistance risk, and caffeine-related effects [5]. A cross-national analysis involving 75 nations carried out by Basu et al. [6] revealed that an increment in soft drink consumption from 9.5 to 11.4 gallons per person per year from 
1997 to 2010 had been linked with the uprising overweight, obesity and diabetes issues at the global scale. Current evidence also suggests that a high consumption of SSBs, particularly the rise in dietary fructose consumption, has contributed to various health outcomes, including weight gain, high blood pressure, insulin resistance, diabetes, and liver disorders such as non-alcoholic steatohepatitis and non-alcoholic fatty liver disease [7]. A meta-analysis showed that every additional one serving per day of SSB intake increased the risk for incident hypertension $(R R=1.08,95 \% C I=1.04,1.12)$ and cardiovascular disease $(\mathrm{RR}=1.17,95 \% \mathrm{CI}=1.10,1.24)$ [8].

Adolescents seem to be the major consumers of SSBs, in which SSBs have become the major contributor of energy intake in their diet [4]. The Internet-based Family Life, Activity, Sun, Health, and Eating (FLASHE) study reported that $67.4 \%$ of adolescents (12-17 years old) in the United States consumed SSBs on a daily basis, 33.9\% took between one and less than two SSBs, and 33.5\% consumed two or more SSBs daily [9]. Likewise, the Ontario Student Drug Use and Health Survey revealed that 81.4 and $12.0 \%$ of middle- and high-school students (11-20 years old) consumed at least one SSB and energy drink during the preceding week, respectively [10]. In Malaysia, the National Health and Morbidity Survey (NHMS) 2011 discovered that 15.1\% of adolescents consumed two or three cups of drinks with sweetened condensed milk per day [11]. The Global School-based Student Health Survey (GSHS) in 2012 found that 29.3\% of Malaysian adolescents aged between 13 and 17 consumed carbonated soft drinks one or more times per day [12]. In terms of the amount of SSBs consumed, the Western Australia Pregnancy Cohort (Raine) Study reported that the consumption of SSBs was $335 \mathrm{~g} /$ day or 1.3 serving/day among adolescents aged between 14 and 17 [13]. In the Netherlands, the average SSB intake among children aged between 6 and 13 was $900 \mathrm{~mL} /$ day [14]. These findings suggest that the constant SSB intake poses a problem among adolescents globally and this uprising scenario warrants further investigation.

A number of prior studies have explored the factors associated with SSB consumption among adolescents, such as physical activity level $[4,15,16]$, screen viewing $[4,17,18]$, sleep quality [18], fast food intake [4,16], availability of SSBs at home [14,19,20], parenting practices [14,19], peer influence [19,20], and obesity [21]. Nevertheless, these reported findings appear to be inconsistent. Therefore, more studies are needed to correlate these identified factors with SSB consumption. Furthermore, only a handful of studies have looked into factors associated with SSB consumption among adolescents in Malaysia. As such, this study assessed the associations of lifestyle factors (physical activity level, screen-viewing behavior, sleep quality, and frequency of eating a meal or snack at fast food restaurant), socio-environmental factors (home food availability, peer social influence, and parenting practice), and body weight status with consumption of SSBs among adolescents. Extensive understanding of the factors related to SSB intake is an integral issue that can be of assistance in devising an effective nutrition-related intervention program to promote healthy lifestyle and eating behaviors among adolescents.

\section{Materials and Methods}

\subsection{Participants}

The probability proportional to size (PPS) sampling technique had been employed as the sampling method in this study. A list of 30 government public schools located within the Gombak district in Selangor state was obtained from the Malaysian Ministry of Education. Based on the PPS, a secondary school was randomly selected. Adolescents who were physically disabled and experienced learning disabilities or developmental delays were excluded from this study. Out of 604 eligible adolescents aged between 12 and 16, 501 agreed to participate in this study. A total of 421 adolescents were retained in the final analysis, since a number of adolescents failed to complete the questionnaires.

Ethics approval was obtained from the Ethics Committee for Research Involving Human Subjects, Universiti Putra Malaysia (Reference No.: JKEUPM-2017-172). Permission to carry out the study was 
granted from the Malaysian Ministry of Education and the Selangor Department of Education. Written informed consent forms were collected from each participant and their guardians.

\subsection{Measures}

A set of Malay language self-administered questionnaires was completed by the participants to retrieve information pertaining to their sociodemographic background, lifestyle factors (physical activity, screen-viewing behavior, sleep quality, and frequency of eating a meal or snack at a fast food restaurant), socio-environmental factors (home food availability of SSB, peer social pressure and parenting practice), and consumption of SSBs. Additionally, the height and weight of the participants were measured by the researcher.

\subsubsection{Sociodemographic Background}

Self-reported information, such as age, sex, ethnicity, parent's education level, monthly household income, and daily pocket money, were obtained from the participants.

\subsubsection{Intake of Sugar-Sweetened Beverages}

The participants were required to report the frequency of SSB consumption on a weekly basis (for the past one week) and the amount of SSB intake in daily basis. The SSBs included fruit drinks, regular carbonated flavored drinks, isotonic drinks, soft drink bases, syrups, botanical beverage mixes, soy bean milk/drinks, cow's milk, cultured milk, sweetened tea, instant coffee, and malted drinks, in accordance to Food Regulation 1985 [22] and MANS 2014 [23]. The amount of SSB consumption per day was based on household measurement $(1$ glass $=250 \mathrm{~mL}, 1 \mathrm{can}=325 \mathrm{~mL}$, and 1 bottle $=500 \mathrm{~mL}$ ). The amount of SSB consumption per day was determined by using the formula suggested by Tak et al. [24]:

Volume $(\mathrm{mL} /$ day $)=($ No. of days $\times$ total amount of beverages consumed $) / 7$ days

\subsubsection{Physical Activity}

The Physical Activity Questionnaire for Older Children (PAQ-C) [25] was used to assess physical activity level amongst the participants in the past seven days. The PAQ-C consisted of nine items. Item 1 was on spare time activities, while items 2 to 8 were regarding physical activity level during physical education class, recess, lunch, right after school, evening, and weekends. Lastly, item 9 was about the frequency of physical activities performed daily. The final PAQ-C activity summary score was obtained from the mean value of the total 9 items. A higher score in the PAQ-C indicated a higher physical activity level. Physical activity level was categorized into 'low' (1-2.33), 'moderate' (2.34-3.66), and 'high' (3.67-5.00) [26]. The Malay version of the PAQ-C applied in this study has been reported to be valid and reliable among Malaysian students aged between 10 and 17 [27].

\subsubsection{Screen-Viewing Behavior}

Screen time was assessed by asking as to the frequency of watching television (including videos) and playing on smartphones or computer/video games during weekdays and weekends [18]. The total screen time was calculated by using the following formula:

Total screen time per day (hours) $=5 / 7 \times($ reported hours of PC + TV + smartphone time on weekdays) $+2 / 7 \times$ (reported hours of PC $+\mathrm{TV}+$ smartphone time on weekend days)

\subsubsection{Sleep Quality}

The 19-item Pittsburgh Sleep Quality Index (PSQI) [28] was used in this study to measure sleep quality. The PSQI consisted of seven components, namely, subjective sleep quality, sleep latency, 
sleep duration, habitual sleep efficiency, sleep disturbances, use of sleeping medication, and daytime dysfunction. The score for each component ranged between 0 and 3 . The summation score, or better known as the Global PSQI Score, ranged from 0 to 21. A higher score indicated poorer sleep quality, while a global score of $>5$ was considered as "poor sleepers" and $\leq 5$ reflected "good sleepers". The validated Malay version of the PSQI [29] was employed in this study. The Cronbach's alpha coefficient for this study was 0.634 , indicating acceptable internal consistency reliability.

\subsubsection{Visiting Fast Food Restaurants}

The frequency of eating a meal or snacking at fast food restaurants was assessed by using a single question derived from the GSHS Malaysia [12]: "During the past 7 days, on how many days did you eat food from a fast food restaurant, such as McDonalds, KFC and Pizza Hut?". The response ranged from 0 to 7 days a week.

\subsubsection{Home Food Availability}

The three subscales in the Project EAT survey [30], namely, healthy home food availability (5 items), unhealthy home food availability (4 items), as well as fruits and vegetables availability (5 items), were applied in this study. A 4-point Likert scale, from 1 (never available) to 4 (always available), was used. The score was calculated by summing the scores for all the items under each subscale. A higher score for a subscale indicated higher food availability for the food items represented by that particular subscale. In this study, the Cronbach's alpha coefficient for healthy home food availability subscale was 0.707 , unhealthy home food availability subscale was 0.771 , while fruits and vegetables availability subscale was 0.739 , thus signifying good internal consistency reliability.

\subsubsection{Peer Social Influence}

Peer social influence was evaluated by using two questions derived from Luszczynska et al. [20]: 'My friend discourages from eating snacks or drinking fizzy drink, lemonade or energy drink' and 'My friend disapproves of my eating snack or drinking fizzy drink'. The responses applied a 5-point Likert scale, from 1 (strongly disagree) to 5 (strongly agree). The mean score was calculated from the two questions. A higher score indicated higher peer social influence on the consumption of SSBs. The Spearman-Brown coefficient for this scale was 0.741 , indicating good internal consistency reliability.

\subsubsection{Parenting Practices}

Perceived restrictive food parenting practice was measured by using a 9-item questionnaire [31]. Parenting practice towards dietary behavior on SSB consumption for fathers and mothers was examined by employing two sets of similar questions (4 items). The final item was regarding the availability of SSBs at home. A 5-point Likert scale was used, from strongly disagree (1) to strongly agree (5). Additionally, a reversed score was applied for items 5, 6, and 9. A summation score was calculated by summing the score for all the items. A higher score indicated greater restrictive food parenting practice. In this study, the Cronbach's alpha coefficient for restrictive food parenting practice was 0.601 , signifying acceptable internal consistency reliability.

\subsection{Anthropometric Measurements}

The height of the participants was measured by using a SECA 206 Body Meter (SECA, Hamburg, Germany), while the weight was measured by using a TANITA Digital Weight Scale HD-319 (TANITA Corporation, Arlington Heights, IL, USA). All the anthropometric measurements were taken twice to compute their mean values. Body mass index-for-age z-scores (BAZ) of the participants were calculated by using the WHO AnthroPlus Version 1.0.4 software (WHO, Geneva, Switzerland). The classification of BAZ adhered to the WHO Growth Reference 2007 [32]. 


\subsection{Statistical Analysis}

IBM SPSS Statistics 24 (IBM SPSS Statistic, Inc., Chicago, IL, USA) was applied to perform all statistical analyses. Numerical descriptive data were presented in means, standard deviations, medians, and interquartile ranges, while categorical descriptive data were presented in count (n) and proportion (\%). Simple linear regression was applied to determine the factors associated with the consumption of SSBs. All variables with $p<0.25$ in the simple linear regression model were included in the multiple linear regression model. The significance level was set at $p<0.05$.

\section{Results}

Table 1 shows the characteristics of the participants. A total of 421 participants with a mean age of $13.3 \pm 1.3$ years participated in this study. Almost all the participants were Malays (97.9\%). The mean value for self-reported daily pocket money was MYR $5.29 \pm 2.44$ ( $\approx 1.30$ USD). A series of unhealthy lifestyle behaviors were reported by the participants. Two-thirds of the participants (68.1\%) had low physical activity level, while one-third of them (35.9\%) were poor sleepers. The total screen time of the participants was $3.67 \pm 1.87 \mathrm{~h}$ daily. A total of $79.0 \%$ of the participants consumed fast food in the previous week. The prevalence of overweight, obesity, and severe obesity were 18.1,15.7, and $4.0 \%$, respectively.

Table 1. Characteristics of the participants $(n=421)$.

\begin{tabular}{|c|c|c|}
\hline Characteristic & $n(\%)$ & Mean \pm SD \\
\hline \multicolumn{3}{|l|}{ Sex } \\
\hline Male & $176(41.8)$ & \\
\hline Female & $245(58.2)$ & \\
\hline Age (years) & & $13.30 \pm 1.28$ \\
\hline 12 & $148(35.2)$ & \\
\hline 13 & $136(32.4)$ & \\
\hline 14 & $14(3.1)$ & \\
\hline 15 & $109(26.0)$ & \\
\hline 16 & $14(3.3)$ & \\
\hline \multicolumn{3}{|l|}{ Ethnicity } \\
\hline Malay & $412(97.9)$ & \\
\hline Chinese & $2(0.5)$ & \\
\hline Indian & $2(0.5)$ & \\
\hline Others & $5(1.2)$ & \\
\hline Daily pocket money (MYR) & & $5.29 \pm 2.44$ \\
\hline \multicolumn{3}{|c|}{ Father's education level $(n=356)$} \\
\hline No formal education & $10(2.8)$ & \\
\hline Primary education & $6(1.7)$ & \\
\hline Secondary education & $272(76.4)$ & \\
\hline Tertiary education & $68(19.1)$ & \\
\hline \multicolumn{3}{|c|}{ Mother's education level $(n=358)$} \\
\hline No formal education & $12(3.4)$ & \\
\hline Primary education & $8(2.2)$ & \\
\hline Secondary education & $263(73.4)$ & \\
\hline Tertiary education & $75(21.0)$ & \\
\hline \multicolumn{3}{|c|}{ Monthly household income $(n=348)$} \\
\hline$<$ MYR2300.00 & $105(30.2)$ & \\
\hline MYR2300.00-5599.99 & $145(41.7)$ & \\
\hline$\geq$ MYR5600.00 & $98(28.2)$ & \\
\hline
\end{tabular}


Table 1. Cont.

\begin{tabular}{lcc}
\hline \multicolumn{1}{c}{ Characteristic } & $\boldsymbol{n} \mathbf{( \% )}$ & Mean \pm SD \\
\hline Physical activity total score & & $2.13 \pm 0.51$ \\
Low & $280(68.1)$ & \\
Moderate & $128(31.1)$ & \\
High & $3(0.7)$ & \\
\hline
\end{tabular}

Screen-viewing behavior (hours/day)

Watch TV/VCD/DVD/music video

Weekday $\quad 2.23 \pm 1.49$

Weekend $\quad 3.66 \pm 2.00$

Total $\quad 2.54 \pm 1.39$

Play smartphone/computer/video game

Weekday $\quad 1.05 \pm 1.25$

Weekend $\quad 1.81 \pm 1.77$

Total $1.19 \pm 1.15$

Total screen time $\quad 3.67 \pm 1.87$

\begin{tabular}{|c|c|}
\hline Sleep quality & \\
\hline Poor & $140(35.9)$ \\
\hline Good & $250(64.1)$ \\
\hline
\end{tabular}

Frequency of eating a meal or snack at fast food restaurant in the past 7 days

$1.57 \pm 1.31$

$\begin{array}{lc}\text { None } & 88(21.0) \\ 1 \text { day } & 155(36.9) \\ 2 \text { days } & 64(15.2) \\ 3 \text { days } & 94(22.4) \\ >3 \text { days } & 19(4.5)\end{array}$

\begin{tabular}{lc}
\hline Home food availability & \\
Healthy home food availability & $13.31 \pm 3.31$ \\
Unhealthy home food availability & $8.82 \pm 2.72$ \\
Fruit and vegetable availability & $13.35 \pm 3.40$ \\
\hline Peers social influence & $5.38 \pm 2.19$ \\
\hline Parenting practice & $26.99 \pm 5.30$ \\
\hline BMI-for-age z-scores & $0.52 \pm 1.58$ \\
Severe thinness & \\
Thinness & \\
Normal & $5(1.2)$ \\
Overweight & $18(4.3)$ \\
Obesity & $238(56.7)$ \\
Severe obesity & $76(18.1)$ \\
\hline SD = Standard Deviation; MYR = Malaysian Ringgit (USD 1 = MYR 4.14 as on 3 May 2019).
\end{tabular}

The mean total amount for daily consumption of SSBs was $1038.15 \pm 725.55 \mathrm{~mL}$ (Table 2), approximately equal to 4 servings of intake $(1$ serving $=250 \mathrm{~mL})$ in a day. The most popular SSB consumed by the participants was malted drinks, followed by milk and tea, whilst the least popular SSBs were instant coffee and botanical beverages. In fact, malted drinks (14.7\%) and cow's milk (11.9\%) were consumed on a daily basis (Table 3). Nearly one-third of the participants (31.4\%) did not consume fruit juice/fruit drink in a week. 
Table 2. Total amount of sugar-sweetened beverage (SSB) intake in a day (mL/day).

\begin{tabular}{lccc}
\hline \multicolumn{1}{c}{ Types of Beverages } & Mean \pm SD & Median & Interquartile Range \\
\hline Fruit juice drink/Fruit drink & $97.45 \pm 135.01$ & 71.43 & $0.00-142.86$ \\
\hline Regular carbonated flavored drink & $70.68 \pm 119.28$ & 35.71 & $0.00-71.43$ \\
\hline Isotonic drink & $66.49 \pm 111.98$ & 35.71 & $0.00-71.43$ \\
\hline Soft drink base/Concentrate & $41.60 \pm 92.90$ & 0.00 & $0.00-35.71$ \\
\hline $\begin{array}{l}\text { Syrup/Cordial (e.g., rose syrup, } \\
\text { lychee cordial, grape cordial) }\end{array}$ & $85.71 \pm 153.78$ & 35.71 & $0.00-107.14$ \\
\hline $\begin{array}{l}\text { Botanical beverages mix (e.g., } \\
\text { Chrysanthemum tea, winter } \\
\text { melon tea) }\end{array}$ & $67.82 \pm 127.00$ & 0.00 & $0.00-71.43$ \\
\hline Soya bean drink/Soya bean milk & $74.32 \pm 162.50$ & 0.00 & $0.00-92.86$ \\
\hline Cow's milk & $175.78 \pm 251.77$ & 92.86 & $0.00-225.00$ \\
\hline Cultured milk/Yogurt drink & $120.62 \pm 150.66$ & 71.43 & $0.00-178.57$ \\
\hline $\begin{array}{l}\text { Tea (e.g., green tea, black tea, red } \\
\text { tea) }\end{array}$ & $165.46 \pm 233.61$ & 71.43 & $0.00-250.00$ \\
\hline Instant coffee & $55.93 \pm 123.85$ & 0.00 & $0.00-46.43$ \\
\hline Malted drink & $192.05 \pm 230.17$ & 107.14 & $35.71-250.00$ \\
\hline \begin{tabular}{l} 
Total SSB (without Cow's milk) \\
\hline
\end{tabular} & $1038.15 \pm 725.55$ & 900.00 & $464.29-1469.64$ \\
\hline
\end{tabular}

Table 3. Frequency of sugar-sweetened beverage (SSB) intake in a week.

\begin{tabular}{|c|c|c|c|c|c|c|c|c|}
\hline \multirow{3}{*}{ Types of Beverages } & \multicolumn{8}{|c|}{$n(\%)$} \\
\hline & \multicolumn{8}{|c|}{ On How Many Days a Week Do You Usually Drink Beverages Below? } \\
\hline & 0 day & 1 day & 2 days & 3 days & 4 days & 5 days & 6 days & 7 days \\
\hline $\begin{array}{l}\text { Fruit juice drink/Fruit } \\
\text { drink }\end{array}$ & $132(31.4)$ & $106(25.2)$ & $97(23.0)$ & $47(11.2)$ & $17(4.0)$ & $9(2.1)$ & $3(0.7)$ & $10(2.4)$ \\
\hline $\begin{array}{l}\text { Regular carbonated } \\
\text { flavored drink }\end{array}$ & $192(45.6)$ & $125(29.7)$ & $56(13.3)$ & $25(5.9)$ & $12(2.9)$ & $5(1.2)$ & $2(0.5)$ & $4(1.0)$ \\
\hline Isotonic drink & $195(46.3)$ & $111(26.4)$ & $60(14.3)$ & $31(7.4)$ & $8(1.9)$ & $6(1.4)$ & $1(0.2)$ & $9(2.1)$ \\
\hline $\begin{array}{l}\text { Soft drink } \\
\text { base/Concentrate }\end{array}$ & $193(45.8)$ & $111(26.4)$ & $61(14.5)$ & $33(7.8)$ & $7(1.7)$ & $5(1.2)$ & $4(1.0)$ & $7(1.7)$ \\
\hline $\begin{array}{l}\text { Syrup/Cordial (e.g., rose } \\
\text { syrup, lychee cordial, } \\
\text { grape cordial) }\end{array}$ & $171(40.6)$ & $106(25.2)$ & $59(14.0)$ & $36(8.6)$ & $15(3.6)$ & $11(2.6)$ & $5(1.2)$ & $18(4.3)$ \\
\hline $\begin{array}{l}\text { Botanical beverages mix } \\
\text { (e.g., Chrysanthemum } \\
\text { tea, winter melon tea) }\end{array}$ & $218(51.8)$ & $93(22.1)$ & 39 (9.3) & $30(7.1)$ & $17(4.0)$ & $8(1.9)$ & $4(1.0)$ & $12(2.9)$ \\
\hline $\begin{array}{l}\text { Soya bean drink/Soya } \\
\text { bean milk }\end{array}$ & $202(48.0)$ & $97(23.0)$ & $50(11.9)$ & $34(8.1)$ & $14(3.3)$ & $9(2.1)$ & $8(1.9)$ & $7(1.7)$ \\
\hline Cow's milk & $100(23.8)$ & $85(20.2)$ & $56(13.3)$ & $64(15.2)$ & $31(7.4)$ & $25(5.9)$ & $10(2.4)$ & 50 (11.9) \\
\hline $\begin{array}{l}\text { Cultured milk/Yogurt } \\
\text { drink }\end{array}$ & 112 (26.6) & $99(23.5)$ & 57 (13.5) & 50 (11.9) & $43(10.2)$ & $24(5.7)$ & $7(1.7)$ & $29(6.9)$ \\
\hline $\begin{array}{l}\text { Tea (e.g., green tea, } \\
\text { black tea, red tea) }\end{array}$ & $116(27.6)$ & 83 (19.7) & 55 (13.1) & $50(11.9)$ & $30(7.1)$ & $22(5.2)$ & $20(4.8)$ & 45 (10.7) \\
\hline Instant coffee & $247(58.7)$ & $85(20.2)$ & $28(6.7)$ & $23(5.5)$ & $15(3.6)$ & $6(1.4)$ & $3(0.7)$ & $14(3.3)$ \\
\hline Malted drink & $71(16.8)$ & $76(18.1)$ & $68(16.2)$ & $59(14.0)$ & $37(8.8)$ & $30(7.1)$ & $18(4.3)$ & $62(14.7)$ \\
\hline
\end{tabular}

The results obtained from multiple linear regression revealed that younger age $(\beta=-0.204$, $p<0.001)$, higher physical activity $(\beta=0.125, p=0.022)$, higher screen time $(\beta=0.147, p=0.007)$, poorer 
sleep quality $(\beta=0.228, p<0.001)$, and unhealthy home food availability $(\beta=0.118, p=0.032)$ were associated with higher SSB intake (Table 4).

Table 4. Factors associated with sugar-sweetened beverages among adolescents.

\begin{tabular}{|c|c|c|c|c|c|c|c|c|c|c|}
\hline \multirow{3}{*}{ Characteristics } & \multicolumn{5}{|c|}{ Simple Linear Regression } & \multicolumn{5}{|c|}{ Multiple Linear Regression } \\
\hline & \multirow[t]{2}{*}{ B } & \multirow[t]{2}{*}{ Beta } & \multicolumn{2}{|c|}{$95 \%$ CI } & \multirow[t]{2}{*}{$p$-Value } & \multirow[t]{2}{*}{ B } & \multirow[t]{2}{*}{ Beta } & \multicolumn{2}{|c|}{$95 \% \mathrm{CI}$} & \multirow[t]{2}{*}{$p$-Value } \\
\hline & & & $\begin{array}{l}\text { Lower } \\
\text { Bound }\end{array}$ & $\begin{array}{l}\text { Upper } \\
\text { Bound }\end{array}$ & & & & $\begin{array}{l}\text { Lower } \\
\text { Bound }\end{array}$ & $\begin{array}{l}\text { Upper } \\
\text { Bound }\end{array}$ & \\
\hline Age & -101.624 & -0.178 & -155.555 & -47.692 & $<0.001$ & -108.230 & -0.204 & -165.904 & -50.556 & $<0.001$ \\
\hline Sex & -248.690 & -0.169 & -387.743 & -109.637 & $<0.001$ & & & & & \\
\hline Daily pocket money & 38.957 & 0.130 & 9.357 & 68.558 & 0.010 & & & & & \\
\hline Physical activity & 214.163 & 0.150 & 77.125 & 351.201 & 0.002 & 171.581 & 0.125 & 24.751 & 318.411 & 0.022 \\
\hline Screen time & 66.060 & 0.173 & 26.779 & 105.341 & 0.001 & 56.013 & 0.147 & 15.185 & 96.842 & 0.007 \\
\hline Sleep quality & 60.913 & 0.196 & 30.469 & 91.357 & $<0.001$ & 68.441 & 0.228 & 35.565 & 101.318 & $<0.001$ \\
\hline $\begin{array}{l}\text { Frequency of eating at } \\
\text { fast food restaurants }\end{array}$ & 98.774 & 0.179 & 46.439 & 151.109 & $<0.001$ & & & & & \\
\hline $\begin{array}{l}\text { Healthy home food } \\
\text { availability }\end{array}$ & -0.459 & -0.002 & -21.839 & 20.922 & 0.966 & & & & & \\
\hline $\begin{array}{l}\text { Unhealthy home food } \\
\text { availability }\end{array}$ & 42.890 & 0.160 & 17.358 & 68.422 & 0.001 & 31.372 & 0.118 & 2.713 & 60.031 & 0.032 \\
\hline $\begin{array}{l}\text { Fruit and vegetable } \\
\text { availability }\end{array}$ & 1.488 & 0.007 & -19.330 & 22.306 & 0.888 & & & & & \\
\hline Peers social influence & -29.323 & -0.088 & -61.403 & 2.757 & 0.073 & & & & & \\
\hline Parenting practice & -2.701 & -0.020 & -16.026 & 10.624 & 0.690 & & & & & \\
\hline BMI-for-age z-scores & -43.379 & -0.094 & -87.350 & 0.592 & 0.053 & & & & & \\
\hline
\end{tabular}

\section{Discussion}

A high consumption of SSBs was observed in this study. The finding appears to exceed that reported in a local study that involved secondary school students in Kuala Lumpur, wherein the mean consumption was reported to be $177.5 \mathrm{~mL}$ per day [33]. A study in the Netherlands among children aged between 6 and 13 revealed that the consumption of SSBs was $900 \mathrm{~mL}$ per day [14], which is slightly lower than that retrieved in the present study. Nevertheless, it is essential to acknowledge that a comparison between studies has to be made cautiously as the variances that exist between the studies may be attributable to the varying definition, measurement, and classification of SSBs. For instance, SSBs in Loh et al. [33] referred to carbonated drinks, sugar-sweetened fruit drinks, non-dairy beverages, and tetra-packed drinks, while the present study embedded more groups of sweetened beverages. The most frequently consumed SSB among adolescents in this study was malted drink, which is consistent with that claimed by the MyBreakfast study [34]. Malted drink is manufactured by mixing malt with other cereal and legume flour with or without whole milk or milk powder and/or cocoa powder, in which malted drink consumers were found to have a significantly higher intake of carbohydrates and micronutrients, when compared to non-consumers [34]. Nonetheless, one should be concerned about the sugar content in malted drink.

The consumption of SSBs among school-aged adolescents in this study seemed to decrease with age. A systematic review performed by Winpenny et al. [35] suggested that the intake of added sugar decreased by age due to the increasing sensitivity in physiological mechanisms towards sucrose, hence the reduction in preference for a sweet taste. On the contrary, several studies reported a positive correlation between age and consumption of SSBs [20,36].

This study found that higher physical activity was linked with higher SSB consumption. This result is in agreement with other studies conducted in Texas [15] and Spain [37] among school-aged adolescents. This association may reflect the belief held by adolescents on the benefits of isotonic 
beverages or sport drinks that aid in water and electrolyte recovery, apart from promoting optimal fitness during or after performing physical activity [38].

A higher screen time was related to a higher consumption of SSBs. Similar findings were reported by Wang et al. [39], in which the study found that consuming carbonated drinks at or more than three times was positively linked with high screen time among school-aged adolescents in Zhejiang Province, China. Likewise, another study found that watching television (2.72 times) and other screen times (smartphones, tablets, computers, and/or playing video games (1.98 times)) for five or more hours daily exerted higher tendency to be exposed to higher consumption of SSBs among American high school students [40]. Such an unhealthy association was believed to be influenced by a high exposure to food and beverage advertisements during screen time [18]. At the same time, they paid less attention to what they ate during screen time, which could eventually lead to overconsumption [18].

Poor sleep quality increased the consumption of SSBs among school-aged adolescents in this study. Several past studies reported similar findings $[4,18,41]$. Several hypotheses have been proposed to explain this association [41]. First, children who slept more had less time to eat. Second, more sleep time reduced screen time and directly reduced their exposure to food and beverages advertisements on televisions and internets. Third, it might be due to the neurohormonal changes that led to reduced sleep time but increased appetite and calorie intake. This particular association could also be due to the intention of short sleepers to consume caffeinated SSBs in order to increase their alertness and to stave off their sleepiness; that is, the excessive consumption of caffeine reduced sleep time [42].

Unhealthy home food availability increased the consumption of SSBs. This finding is in line with other studies $[14,19,20,42]$. The availability of SSBs at home increased accessibility and eased consumption among adolescents. Parents might influence SSB intake among adolescents as they are the main purchaser in a household [13]. Parents serve as role models and facilitators in impacting children's diets [14]. A high consumption of SSBs among adolescents could be due to lack of parental rules at home that limit the consumption of SSBs [42]. Nevertheless, parenting practices in the present study was not associated with a higher consumption of SSBs. Perhaps parents were less likely to implement restrictive parenting practices because the children tend to break rules and therefore they seemed ineffective, hence parents allowing their children to consume one to two SSBs on a daily basis [42]. Lack of knowledge pertaining to the negative consequences of SSBs and lack of motivation or parenting skills might function as the promoting factors to a high consumption of SSBs [42].

Contrary to other studies $[6,21,36]$, an insignificant association was discovered between BAZ and SSB consumption among adolescents in this study, which is in agreement with other studies $[4,43]$. The insignificant findings are attributed to the possibility of overweight and obese adolescents who under-reported their SSB intake or a strategy for them to reduce their SSB intake in light of reducing weight [4]. Several confounding factors, such as dieting and body image perception that might influence body weight status, could play an important role in their association with SSB intake, but the variables were omitted from the present study. Furthermore, emerging evidence reveals that frequent SSB consumption is associated with abdominal adiposity, specifically abnormal fat accumulation in visceral adipose tissue [44]. Therefore, abdominal adiposity should be measured in the future in addition of measuring BAZ. More studies are required to confirm the findings.

Several limitations were noted in this study. First, due to the cross-sectional study design, the temporal correlation between risk factors and SSB consumption could not be established. Prospective cohort studies are warranted to support and to verify the findings among school-aged adolescents. Second, this study used a self-reported questionnaire to gather information, which poses a high risk of under- or over-reporting. For instance, the participants had the tendency to under- or overestimate their SSB intake as the outputs relied heavily on their memory to recall the frequency and amount of consumption. The variances in findings of SSB intake may be due to the different definition, measurement, and classification used, primarily because of limited standardized list of SSBs. The other limitation of this study is that the results cannot be generalized to all Malaysian school-aged adolescents because this study only involved adolescents from Gombak, Selangor. Despite these limitations, this 
study explored the associations of lifestyle factors (physical activity level, screen-viewing behavior, sleep quality, and frequency of eating a meal or snack at fast food restaurant), socio-environmental factors (home food availability, peer social influence, and parenting practice), and body weight status with consumption of SSBs among adolescents in Malaysia, which has not been previously reported. In addition, this study evaluated SSB intake by a continuous measure by incorporating the mean consumption in $\mathrm{mL} /$ day. The use of a continuous measure for SSB intake, instead of a dichotomous measure, is preferable to minimize the probability of loss of information [14].

\section{Conclusions}

This study suggests that the daily consumption of SSBs is high among school-aged adolescents. The findings of this study also highlight the unhealthy lifestyle behaviors among school-aged adolescents, such as low physical activity level, high screen time, and poor sleep quality. These unhealthy lifestyles were found to be associated with a high consumption of SSBs. Given the possible negative health outcomes of high SSB intake, it is crucial to ensure efforts in reducing SSB intake among school-aged adolescents. This study points to the need for adolescents to practice a healthy lifestyle, with the aim of reducing SSB intake. Therefore, future interventions may consider incorporating these components in promoting healthy eating behaviors among adolescents. Lifestyle modification is recommended to achieve optimal health and to control the consumption of SSBs among adolescents.

Author Contributions: Conceptualization, W.Y.G. and S.F.M.; Data curation, W.Y.G., S.F.M. and L.S.L.; Formal analysis, S.F.M. and L.S.L.; Investigation, S.F.M.; Methodology, W.Y.G., S.F.M. and L.S.L.; Project administration, W.Y.G. and S.F.M.; Supervision, W.Y.G.; Validation, W.Y.G.; Writing一original draft, L.S.L.; Writing一review and editing, W.Y.G. and S.F.M.

Funding: This research received no external funding.

Acknowledgments: We would like to thank all the students and their parents, school principal, and teachers for their co-operation.

Conflicts of Interest: The authors declare no conflict of interest.

\section{References}

1. Malik, V.S.; Pan, A.; Willett, W.C.; Hu, F.B. Sugar-sweetened beverages and weight gain in children and adults: A systematic review and meta-analysis. Am. J. Clin. Nutr. 2013, 98, 1084-1102. [CrossRef] [PubMed]

2. Hardy, L.L.; Bell, J.; Bauman, A.; Mihrshahi, S. Association between adolescents' consumption of total and different types of sugar-sweetened beverages with oral health impacts and weight status. Aust. N. Z. J. Public Health 2018, 42, 22-26. [CrossRef] [PubMed]

3. Mesirow, M.S.; Welsh, J.A. Changing beverage consumption patterns have resulted in fewer liquid calories in the diets of US children: National Health and Nutrition Examination Survey 2001-2010. J. Acad. Nutr. Diet. 2015, 115, 559-566. [CrossRef] [PubMed]

4. Park, S.; Blanck, H.M.; Sherry, B.; Brener, N.; O'Toole, T. Factors associated with sugar-sweetened beverage intake among United States high school students. J. Nutr. 2012, 142, 306-312. [CrossRef] [PubMed]

5. Bleich, S.N.; Vercammen, K.A. The negative impact of sugar-sweetened beverages on children's health: An update of the literature. BMC Obes. 2018, 5, 6. [CrossRef] [PubMed]

6. Basu, S.; McKee, M.; Galea, G.; Stuckler, D. Relationship of soft drink consumption to global overweight, obesity, and diabetes: A cross-national analysis of 75 countries. Am. J. Public Health 2013, 103, 2071-2077. [CrossRef] [PubMed]

7. Mai, B.H.; Yan, L.J. The negative and detrimental effects of high fructose on the liver, with special reference to metabolic disorders. Diabetes Metab. Syndr. Obes. 2019, 12, 821-826. [CrossRef]

8. Xi, B.; Huang, Y.; Reilly, K.H.; Li, S.; Zheng, R.; Barrio-Lopez, M.T.; Martinez-Gonzalez, M.A.; Zhou, D. Sugar-sweetened beverages and risk of hypertension and CVD: A dose-response meta-analysis. Br. J. Nutr. 2015, 113, 709-717. [CrossRef] 
9. Haughton, C.F.; Waring, M.E.; Wang, M.L.; Rosal, M.C.; Pbert, L.; Lemon, S.C. Home matters: Adolescents drink more sugar-sweetened beverages when available at home. J. Pediatr. 2018, 202, 121-128. [CrossRef]

10. Sampasa-Kanyinga, H.; Hamilton, H.A.; Chaput, J.P. Sleep duration and consumption of sugar-sweetened beverages and energy drinks among adolescents. Nutrition 2018, 48, 77-81. [CrossRef]

11. Institute of Public Health (IPH). National Health and Morbidity Survey 2011 (NHMS 2011); Vol. II: Non-Communicable Disease; Institute for Public Health (IPH), Secretariat National Institutes of Health (NIH), Ministry of Health Malaysia: Kuala Lumpur, Malaysia, 2011.

12. Institute for Public Health (IPH). The National Health and Morbidity Survey: Malaysia Global School-based Student Health Survey 2012; Institute for Public Health (IPH), Secretariat National Institutes of Health (NIH), Ministry of Health Malaysia: Kuala Lumpur, Malaysia, 2012.

13. Ambrosini, G.L.; Oddy, W.H.; Huang, R.C.; Mori, T.A.; Beilin, L.J.; Jebb, S.A. Prospective associations between sugar-sweetened beverage intakes and cardiometabolic risk factors in adolescents. Am. J. Clin. Nutr. 2013, 98, 327-334. [CrossRef] [PubMed]

14. Gaar, V.M.; Grieken, A.; Jansen, W.; Raat, H. Children's sugar-sweetened beverages consumption: Associations with family and home-related factors, differences within ethnic groups explored. BMC Public Health 2017, $17,195$.

15. Ranjit, N.; Evans, M.H.; Byrd-Williams, C.; Evans, A.E.; Hoelscher, D.M. Dietary and activity correlates of sugar-sweetened beverage consumption among adolescents. Pediatrics 2010, 126, e754-e761. [CrossRef] [PubMed]

16. Qobadi, M.; Payton, M. Consumption of sugar-sweetened beverages in Mississippi: Is there a disparity? Behavioral risk factor surveillance system, 2012. Int. J. Environ. Res. Public Health 2017, 14, 228. [CrossRef] [PubMed]

17. Gebremariam, M.K.; Chinapaw, M.J.; Bringolf-Isler, B.; Bere, E.; Kovacs, E.; Verloigne, M.; Stok, F.M.; Manios, Y.; Brug, J.; Lien, N. Screen-based sedentary time: Association with soft drink consumption and the moderating effect of parental education in European children: The ENERGY study. PLoS ONE 2017, 12, e0171537. [CrossRef] [PubMed]

18. Pérez-Farinós, N.; Villar-Villalba, C.; López-Sobaler, A.M.; Saavedra, M.Á.; Aparicio, A.; Sanz, S.; Dios, R.T.; Castrodeza-Sanz, J.J.; Anta, O.R.M. The relationship between hours of sleep, screen time and frequency of food and drink consumption in Spain in the 2011 and 2013 ALADINO: A cross-sectional study. BMC Public Health 2017, 17, 33. [CrossRef] [PubMed]

19. Ansem, W.J.; van Lenthe, F.J.; Schrijvers, C.T.; Rodenburg, G.; Mheen, D. Socio-economic inequalities in children's snack consumption and sugar-sweetened beverage consumption: The contribution of home environmental factors. Br. J. Nutr. 2014, 112, 467-476. [CrossRef]

20. Luszczynska, A.; Wit, J.B.; Vet, E.; Januszewicz, A.; Liszewska, N.; Johnson, F.; Pratt, M.; Gaspar, T.; Matos, M.G.; Stok, F.M. At-home environment, out-of-home environment, snacks and sweetened beverages intake in preadolescence, early and mid-adolescence: The interplay between environment and self-regulation. J. Youth Adolesc. 2013, 42, 1873-1883. [CrossRef]

21. Ha, K.; Chung, S.; Lee, H.S.; Kim, C.I.; Joung, H.; Paik, H.Y.; Song, Y. Association of dietary sugars and sugar-sweetened beverage intake with obesity in Korean children and adolescents. Nutrients 2016, 8, 31. [CrossRef]

22. Food Safety and Quality Division Ministry of Health Malaysia. 2018. Food Regulations 1985: Incorporating latest amendment P.U. (A) 200/2017. Available online: http://fsq.moh.gov.my/v6/xs/page.php?id=72 (accessed on 8 January 2019).

23. Institute of Public Health (IPH). Malaysian Adult Nutrition Survey (MANS) Vol. II: Survey Findings; Institute for Public Health (IPH), Ministry of Health Malaysia: Kuala Lumpur, Malaysia, 2014.

24. Tak, N.I.; Velde, T.S.J.; Oenema, A.; Horst, K.; Timperio, A.; Crawford, D.; Brug, J. The association between home environmental variables and soft drink consumption among adolescents. Exploration of mediation by individual cognitions and habit strength. Appetite 2011, 56, 503-510. [CrossRef]

25. Kowalski, K.C.; Crocker, P.R.E.; Donen, R.M. The Physical Activity Questionnaire for Older Children (PAQ-C) and Adolescents (PAQ-A) Manual; College of Kinesiology, University of Saskatchewan: Saskatoon, SK, Canada, 2004. 
26. Dan, S.P.; Nasir, M.M.T.; Zalilah, M.S. Sex and ethnic differentials in physical activity levels of adolescents in Kuantan. Malays. J. Nutr. 2007, 13, 109-120. [PubMed]

27. Azian, N.M.Z.; Sahril, N.; Omar, A.M.; Ahmad, H.M.; Baharudin, A.; Nor, S.M.N. Reliability and validity of PAQ-C reliability and validity of the Physical Activity Questionnaire for Older Children (PAQ-C) in Malay language. Int. J. Public Health Res. 2016, 6, 670-676.

28. Buysse, D.J.; Reynolds, C.F., III; Monk, T.H.; Berman, S.R.; Kupfer, D.J. The Pittsburgh Sleep Quality Index: A new instrument for psychiatric practice and research. Psychiatry Res. 1989, 28, 193-213. [CrossRef]

29. Yunus, R.M.; Wazid, S.W.; Hairi, N.N.; Choo, W.Y.; Hairi, F.M.; Sooryanarayana, R.; Ahmad, S.N.; Razak, I.A.; Peramalah, D.; Aziz, S.A.; et al. Association between elder abuse and poor sleep: A cross-sectional study among rural older Malaysians. PLoS ONE 2017, 12, e0187782.

30. Laska, M.L.; Larson, N.I.; Neumark-Sztainer, D.; Story, M. Dietary patterns and home food availability during emerging adulthood: Do they differ by living situation? Public Health Nutr. 2010, 13, 222-228. [CrossRef] [PubMed]

31. Kremers, S.; Sleddens, E.; Gerards, S.; Gubbels, J.; Rodenburg, G.; Gevers, D.; van Assema, P. General and food-specific parenting: Measures and interplay. Child. Obes. 2013, 9, S22-S31. [CrossRef] [PubMed]

32. Onis, M.; Onyango, A.W.; Borghi, E.; Siyam, A.; Nishida, C.; Siekmann, J. Development of a WHO growth reference for school-aged children and adolescents. Bull. World Health Organ. 2007, 85, 660-667. [CrossRef] [PubMed]

33. Loh, D.A.; Moy, F.M.; Zaharan, N.L.; Jalaludin, M.Y.; Mohamed, Z. Sugar-sweetened beverage intake and its associations with cardiometabolic risks among adolescents. Pediatr. Obes. 2017, 12, e1-e5. [CrossRef] [PubMed]

34. Mohamed, H.J.; Loy, S.L.; Taib, M.M.N.; Karim, N.A.; Tan, S.Y.; Appukutty, M.; Razak, A.N.; Thielecke, F.; Hopkins, S.; Ong, M.K.; et al. Characteristics associated with the consumption of malted drinks among Malaysian primary school children: Findings from the MyBreakfast study. BMC Public Health. 2015, 15, 1322. [CrossRef]

35. Winpenny, E.M.; Penney, T.L.; Corder, K.; White, M.; Sluijs, E.M.F. Changes in consumption of added sugars from age 13 to 30 years: A systematic review and meta-analysis of longitudinal studies. Obes. Rev. 2017, 18, 1336-1349. [CrossRef]

36. Lee, H.S.; Kwon, S.O.; Lee, Y. Weight status and dietary factors associated with sugar-sweetened beverage intake among Korean children and adolescents Korea National Health and Nutrition Examination Survey, 2008-2011. Clin. Nutr. Res. 2013, 2, 135-142. [CrossRef] [PubMed]

37. Bibiloni, M.M.; Özen, A.E.; Pons, A.; González-Gross, M.; Tur, J.A. Physical activity and beverage consumption among adolescents. Nutrients 2016, 8, 389. [CrossRef] [PubMed]

38. Larson, N.; Wolfe, J.; Story, M.; Neumark-Sztainer, D. Adolescent consumption of sports and energy drinks: Linkages to higher physical activity, unhealthy beverage patterns, cigarette smoking, and screen media use. J. Nutr. Educ. Behav. 2014, 46, 181-187. [CrossRef] [PubMed]

39. Wang, H.; Zhong, J.; Hu, R.; Fiona, B.; Yu, M.; Du, H. Prevalence of high screen time and associated factors among students: A cross-sectional study in Zhejiang, China. BMJ Open 2018, 8, e021493. [CrossRef] [PubMed]

40. Kenney, E.L.; Gortmaker, S.L. United States adolescents' television, computer, videogame, smartphone, and tablet use: Associations with sugary drinks, sleep, physical activity, and obesity. J. Pediatr. 2017, 182, 144-149. [CrossRef] [PubMed]

41. Prather, A.A.; Leung, C.W.; Adler, N.E.; Ritchie, L.; Laraia, B.; Epel, E.S. Short and sweet: Associations between self-reported sleep duration and sugar-sweetened beverage consumption among adults in the United States. Sleep Health 2016, 2, 272-276. [CrossRef] [PubMed]

42. Bogart, L.M.; Cowgill, B.O.; Sharma, A.J.; Uyeda, K.; Sticklor, L.A.; Alijewicz, K.E.; Schuster, M.A. Parental and home environmental facilitators of sugar-sweetened beverage consumption among overweight and obese Latino youth. Acad. Pediatr. 2013, 13, 348-355. [CrossRef] 
43. Yang, L.; Bovet, P.; Liu, Y.; Zhao, M.; Ma, C.; Liang, Y.; Xi, B. Consumption of carbonated soft drinks among young adolescents aged 12 to 15 years in 53 low- and middle-income countries. Am. J. Public Health 2017, 107, 1095-1100. [CrossRef]

44. Ma, J.; Sloan, M.; Fox, C.S.; Hoffmann, U.; Smith, C.E.; Saltzman, E.; Rogers, G.T.; Jacques, P.F.; McKeown, N.M. Sugar-sweetened beverage consumption is associated with abdominal fat partitioning in healthy adults. J. Nutr. 2014, 144, 1283-1290. [CrossRef]

(C) 2019 by the authors. Licensee MDPI, Basel, Switzerland. This article is an open access article distributed under the terms and conditions of the Creative Commons Attribution (CC BY) license (http://creativecommons.org/licenses/by/4.0/). 